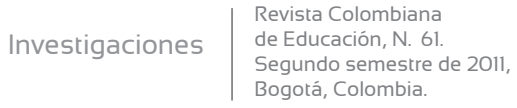

de Educación, N. 61.
Segundo semestre de 2011,

Bogotá, Colombia.

\section{Gonzalo Sánchez: trayectoria de una experiencia de memoria de la violencia en Colombia*}

//Gonzalo Sánchez: A Lifetime of a Colombian Violence Memory //Gonzalo Sánchez: tregetória de uma experiência da memória da violência na Colômbia

Este trabajo forma parte de algunos resultados de investigación adelantados en el Doctorado Interinstitucional en Educación, sede Universidad Pedagógica Nacional.

Docente catedrático Universidad Pedagógica Nacional. Maestría en Educación. jogacral@gmail.com

\section{Resumen}

Este artículo presenta la trayectoria de la experiencia de la memoria de Gonzalo Sánchez, intelectual colombiano que formó parte de la comisión de estudios de la violencia en los años 80 y actualmente dirige el grupo académico Memoria Histórica perteneciente a la Comisión Nacional de Reparación y Reconciliación. Sánchez no solo ha indagado acerca del tema de la violencia, sino que la vivió en carne propia, durante su infancia, por ser originario de una familia campesina afectada de manera directa e indirecta por el conflicto bipartidista de mediados de siglo. Interesa mostrar cómo esa trayectoria de la memoria ha sido marcada también por las apuestas intelectuales y académicas y, asimismo, cómo esas experiencias límite que se recuerdan han incidido o contribuido en los aportes académicos que ha estructurado Sánchez.

\section{Abstract}

This paper shows the experience by Gonzalo Sánchez' memory, a Colombian thinker who was part of a commission on violence study in the 1980's and now leading the academic group Historical Memory of the National Commission for Reparation and Reconciliation. Sanchez has not only questioned violence, but lived himself during his childhood, because he was born in a rural family affected directly and indirectly by the midcentury bipartisan conflict. We want to show how his memory journey has been marked by inteIlectual and academic activities and also how the remembered limit experiences have influenced or helped to Sanchez contribution.
}

\section{Palabras Clave}

Gonzalo Sánchez, trayectorias intelectuales, memoria, violencia en Colombia.

\section{Keywords}

Gonzalo Sánchez, intellectual journeys, memory, violence in Colombia. 


\title{
Resumo
}

\begin{abstract}
Este trabalho mostra a trajetória, por meio da memória, de Gonzalo Sanchez, um pensador colombiano que fez parte da comissão de estudos da violência na década de 1980, e que atualmente é o chefe do grupo de pesquisa de Memória Histórica e é membro da Comissão Nacional de Reparação e Reconciliação. Sanchez não só questionou a violência, mas viveu-a durante sua infância, uma vez que nasceu em uma família camponesa afetada direta e indiretamente pelo conflito bipartidário em meados do século XX. Almejamos mostrar como sua jornada de memória tem sido marcada por atividades intelectuais e acadêmicas, e ainda como as experiências influenciaram ou ajudaram na contribuição de Sanchez.
\end{abstract}

\section{Palavras chave}

Gonzalo Sanchez, jornadas intelectuais, memória, violência na Colômbia

\section{Introducción}

No es fácil dedicarse a pensar sobre acontecimientos traumáticos como la violencia contra movimientos políticos de oposición. En Colombia sigue siendo -además de poco visible- peligroso para el investigador, por la vigencia del conflicto interno y la compleja trama en la que se inscribe esta violencia política que aún se resiste a ser explicada. Pero si podemos escuchar y pensar sobre estos fenómenos es porque toda experiencia de vida (o de muerte) pasa a ser parte integrante de la vida misma de personas o de comunidades, por un rasgo ontológico fundamental del ser humano: la memoria. Si la vida no fuera ella misma memoria, si la memoria no fuera ella misma parte de la vida, no podría siquiera hablarse de experiencias vitales, ni siquiera de historia universal, historia de la humanidad, o de micro o macro historias. No en vano habla el sentido etimológico del término recuerdo: lo asimilado en el corazón, es decir, lo que pasa a convertirse en parte integrante de la vida misma, desde su centro, desde su médula. Esto significa: la memoria misma hace parte de la experiencia de la vida de las personas y la experiencia misma no puede pensarse sin la memoria.

De esta forma, es necesario tomar en cuenta que la memoria también es una experiencia que tiene su trayectoria peculiar. Partiendo de estos presupuestos me interesa saber cuál ha sido la trayectoria de la experiencia de la memoria de un intelectual que no solo ha indagado acerca del tema de la violencia, sino 
que la ha vivido en carne propia. Se trata de Gonzalo Sánchez, originario de una familia campesina afectada de manera directa e indirecta por el conflicto de la Violencia, ${ }^{1}$ quien ha hecho aportes intelectuales a los debates políticos y sociales sobre la realidad conflictiva que vive Colombia, formando parte del equipo de investigadores sobre la violencia $^{2}$ («violentólogos») en los años 80 y recientemente integrando procesos de recuperación de memoria de víctimas, así como procesos de duelo de experiencias traumáticas como actual director del grupo académico Memoria Histórica $(\mathrm{GMH}){ }^{3}$ agenciando numerosos trabajos en esta dirección, que circulan incluso de manera pública por el carácter social que tiene dicha información.

1 En este artículo Violencia, con mayúscula, designa el periodo de la historia colombiana que se detonó con el asesinato de Jorge Eliécer Gaitán y consistió en un cruento enfrentamiento entre los dos partidos tradicionales colombianos - Liberal y Conservador- que involucró a personas de la sociedad civil, entre 1948 y 1960. Sin embargo, los debates sobre la periodización de este momento histórico son innumerables; en el presente trabajo mencionaremos algunos elementos en este sentido.

2 Creado en 1987 por iniciativa del Ministerio de Gobierno y Colciencias para investigar la violencia en el país, trabajo que produjo como fruto el texto Colombia: violencia y democracia.

3 Este grupo académico perteneciente a la Comisión Nacional de Reparación y Reconciliación (CNRR), entidad gubernamental creada hacia el año 2006 en el contexto de la desmovilización de los grupos paramilitares en el 2005, y en el marco de la Ley 975 más conocida como «ley de justicia y paz». Si bien se trata de entidades direccionadas por el Estado, los trabajos del GMH se han destacado por su rigor académico y su «independencia» frente a las políticas oficiales, pues ha procurado visibilizar relatos opacados por las historias oficiales.
Este interrogante indagará, entonces, por la forma como la trayectoria de la memoria ha sido marcada también por las apuestas intelectuales y académicas, pero también cómo esas experiencias límite que se recuerdan han incidido o contribuido en los aportes académicos que ha estructurado Sánchez. Para resolver los interrogantes mencionados, me serviré principalmente de tres fuentes narrativas personales. La primera de ellas (Galindo; Valencia, 1999) se recoge en un texto que recopila las experiencias de la violencia de diferentes investigadores; esta narrativa personal tiene una estructura episódica por cuanto fue fruto de entrevistas realizadas al los violentólogos. En estas narrativas se evidencian procesos de rememoración espontáneos en donde los silencios, las interrupciones, los saltos y las expresiones coloquiales son frecuentes pero dan a entender un sentido y un significado de la vivencia misma. Por esta razón estos testimonios son más valiosos de lo que pareciera en la medida en que dan cuenta de la memoria en su sentido más cercano a la vivencia pura, o, si se quiere, a la «memoria pura». ${ }^{4}$ Las otras dos narrativas perso-

4 Por «memoria pura» me refiero no a que sea más verídica o menos falsa, sino a aquella en su sentido más espontáneo y sin haber sido trabajada por los ejercicios reflexivos o conceptuales complejos de ordenamiento o abstracción que estructuran esos recuerdos. La memoria pura, para mí, tiene lugar en la narrativa espontánea que se da en las conversaciones coloquiales, a través de las cuales recordamos, con allegados, nuestras vivencias mediadas por objetos como las fotografías o por circunstancias determinadas, como los encuentros con los amigos, o, 
nales fueron publicadas por Sánchez $(2003 ; 2004)$, con una estructura académica, fruto de un ejercicio reflexivo, de diferentes épocas y publicadas por distintas motivaciones. Aquí ya no se trata de una memoria pura sino de una memoria «elaborada», «razonada», «organizada». También me sirvo de una narrativa estructurada por otro autor (Pardo, 1995), que sirvió para precisar algunos detalles temporales y locales.

Estructuro esta trayectoria en cuatro grandes experiencias de la memoria que logro identificar, más que como etapas sucesivas, como formas de situarse ante los recuerdos de la violencia: la memoria sobre la experiencia directa con la violencia; la ausencia «académica» en el tema de la violencia, y por lo mismo, el silencio de la memoria; el enfrentamiento obligado con la violencia, en consecuencia, con ciertos recuerdos que la trayectoria intelectual exige de Sánchez; finalmente, la experiencia de reflexión de la memoria misma, en la que se evidencia el giro no hacia los hechos como tal, sino hacia la manera de recordar, que es lo que caracteriza el actual enfoque del campo de la memoria del que he hablado al comienzo.

La mayor parte de la información se encontró gracias a la mano o la voz del propio Gonzalo Sánchez, a quien dirijo mis más sinceros agradecimientos por su orientación en este trabajo.

\section{El desplazamiento forzado como experiencia de la Violencia}

Gonzalo Sánchez nació el 18 de julio de 1945 en el Líbano, Tolima, ${ }^{5}$ hijo de una familia campesina y humilde. Su infancia se desarrolla atravesada por experiencias de violencia que él relata; podemos identificar tres momentos clave: el primero, cuando apenas contaba con entre 4 y 6 años de edad, que se refiere al desplazamiento forzado y a su estadía, unos pocos meses, en Bogotá; el segundo, referido a su vuelta al Líbano; y el tercero, a su etapa de estudiante de bachillerato.

La memoria de la primera experiencia que tiene Sánchez con el conflicto colombiano se refiere a lo que se ha denominado

como en este caso, por una entrevista. En ellas, expresiones como las risas, los llantos, los gestos, hacen parte de la narrativa y, por lo mismo, dan cuenta de la memoria; no solo el lenguaje articulado es evidencia de una memoria.

5 «Nací en 1945, de una familia campesina de muy limitados recursos económicos y culturales, en uno de los principales centros cafeteros de Colombia, el Líbano, Tolima, epicentro de las confrontaciones bipartidistas de mediados del siglo XX» (Sánchez, 2003, p. 11). 
la Violencia: Sánchez sitúa cronológicamente el acontecimiento entre 1950 y 1952, evocando sus recuerdos de infancia con dificultad. ${ }^{6}$ La primera idea de Violencia para Sánchez se estructura a partir de su experiencia vital relacionada con el desplazamiento forzado en dos grandes momentos: uno, en el estar huyendo; y otro, en el estar en la ciudad como un lugar ajeno o extraño (en términos de esa época, exiliado).

Esta memoria de la experiencia de la violencia como desplazamiento forzado comprende cuatro elementos básicos: 1) el sentimiento de intimidación que se ejerce simbólicamente $y$, de hecho, por medio del control del voto para determinar quién está a favor del partido de turno, y que provoca el desplazamiento; ${ }^{7}$ 2) lo precipitado

6 Esta idea la refuerza a lo largo del discurso: más adelante la reafirma: «Bueno, la primera vivencia que yo tengo es... una noche: Líbano, Tolima. 1950, 51, 52. Tengo borrosa la fecha... y una matanza nocturna (...) Realmente tengo borroso eso. Soy del 45, y tenía 5 ó 6 años, algo así. Tengo borroso eso» (Galindo; Valencia, 1999, p. 86).

7 Más adelante dirá Sánchez: «Porque mi padre era liberal y en esa época había el control de las cédulas para ver por quién se había votado en determinada elección. No sé si era una estampilla o qué, pero en todo caso estaba indicado si uno había votado o no en tal año. Y como había años de total abstención liberal, como 1949, se sabía que el que había votado ese año era conservador. El que no, liberal. Entonces, simplemente por ese hecho, una persona podía morir... es la primera gran imagen que yo tengo» (Galindo; Valencia, 1999, p. 85). Como se ve, se trata de una violencia política; para ese entonces existían dos grupos fuertes que se enfrentaban: los chulavitas, que eran campesinos conservadores que ejercieron persecución y masacres contra liberales, y los chusmeros que fueron campesinos liberales que se armaron para de la huida de la tierra natal en medio de sentimientos de intimidación y zozobra, a la vez que el temor de ser encontrado y asesinado por el motivo anteriormente descrito; ${ }^{8} 3$ ) la confusión ${ }^{9}$ que implica mantenerse en esa zozobra constante del primer elemento y la angustia intensa del segundo; $;^{10}$ 4) consecuencias sociales de ese desarraigo.

Este último elemento se desglosa en varios aspectos que se rememoran: el rebusque del sustento en la

defenderse de los chulavitas.

8 «Nosotros estamos saliendo ya del Líbano para algún otro sitio del país, de huida de la Violencia. Mi padre amenazado. No se sabe (sic.) que hay posibilidades de que lo vayan a asesinar esa misma noche. Entonces, precipitadamente, salimos. Mi familia vivía en el campo en ese momento. Mi padre era un campesino, administrador de una gran finca de un hacendado ganadero [Finca El Agrado (Pardo, 1995, p. 683)]. Entonces salimos de la noche a la mañana, sin tiempo de vender ni las gallinas, ni los marranos ni nada de lo que había en la casa, sino simplemente armando el dinero suficiente para el pasaje» (Galindo; Valencia, 1999, p. 85)

9 «Esa es la escena con la cual yo asocio el inicio de la Violencia: subiéndonos a una chiva a las tres o cuatro de la mañana rumbo a Bogotá. Todos venimos rumbo a Bogotá... ¡ ¡in saber a qué, sin saber a dónde! Con mucho susto en el camino porque uno no sabía hasta dónde iba a llegar. Y recuerdo muy bien esta confusión que para mí es una confusión indicativa del hecho "violencia": de la percepción de un niño de la violencia, que todavía no identifica materialmente una cantidad de símbolos ya socialmente construidos» (Galindo; Valencia, 1999, p. 85).

10 «Para mí el primer retén fue un susto tenebroso. Eran los retenes regulares de control vial. Y cada vez que paraba la chiva esa donde íbamos todos amontonados, con la familia de un hermano de mi padre, es decir, con toda una cantidad de primitos, sentía que "aquí nos paran para matarnos". La sensación era de que a lo largo de todo el trayecto le estábamos huyendo a la muerte pero también estábamos encontrándonos con la muerte, hasta el momento en que llegamos a Bogotá» (Galindo; Valencia, 1999, p. 85). 
ciudad, ${ }^{11}$ que implica el surgimiento o el crecimiento de nuevos barrios de «invasión» ${ }^{12}$; la situación de la infancia desplazada asumida por instituciones de asistencia social que generó otro tipo de experiencias traumáticas ${ }^{13}$; la experiencia de desarraigo ${ }^{14}$ que ocasionó la enfermedad del padre de Sánchez, «a tal punto de que estuvo cerca de perder el juicio» (Sánchez, 2003, p. 12); y finalmente la devaluación de las tierras en el campo, que paradójicamente puede ser ventajosa ${ }^{15}$.

La segunda etapa, la de la vuelta a la tierra natal, se presenta en la memoria de Sánchez como inevitable para una familia cuya esencia es la tierra: ella da el sustento; ella da la vida; ella es el seno de la existencia. Sin embargo, la experiencia de la Violencia no terminó para Sánchez allí; en esta etapa la vivencia de la Violencia cambia; ya no se trata de una huída pavorosa y

11 El papá de Sánchez «Montó un toldo por allá en el [barrio] Siete de Agosto para revender maíz. Compraba por bultos para vender por libras, ¿cierto? Yo no sé a dónde iba: salía a las tres o cuatro de la mañana, tenía que atravesar Bogotá. Tal vez iba a San Victorino. Allí compraba, y luego debía amanecer a las cinco o seis en el Siete de Agosto, donde montaba su toldo. Recuerdo, porque eso me suena: Siete de Agosto... Siete de Agosto. Montábamos en el bus y ahí decía "Siete de Agosto" » (Galindo; Valencia, 1999, p. 85)

12 El Barrio Siete de Agosto pertenece a la Localidad Barrios Unidos de Bogotá; y surgió como invasión en 1935, «Este territorio estaba antes conformado por extensas haciendas, entre ellas la del expresidente Miguel Abadía Méndez; la finca San León, de los hermanos cristianos, en lo que hoy es el barrio Los Alcázares; la Quinta de Mutis, denominada así por haber sido en el siglo XVII un lugar de vivienda y estudio del sabio José Celestino Mutis, de propiedad del Colegio Mayor del Rosario» (Historia del poblamiento de Barrios Unidos. Recuperado el 12 de noviembre de 2010 en http://www.bogota.gov. co/portel/libreria/php/x_frame_detalle.php?id=40276). La invasión se acrecentó debido a la masiva migración del campo a la ciudad en los años cincuenta.

13 «Fuimos a dar aquí en Bogotá a una cosa que se llamaba el Amparo de Niños, un centro que todavía existe [véase http://www.amparodeninos.org.co]. Una especie de refugio creado por la mujer de López Pumarejo, que estaba como recién abierto. Es como una especie de refugio para migrantes, se suponía, liberales. Yo no sé cómo mi padre se levantó esa cosa. El hecho era simplemente podernos garantizar la comida y, pues, ¡bienvenida!, ¿no? Pues si se consigue la comida y la dormida para los pelados, uno ya se acomoda»; más tarde, Sánchez agrega que en esa institución «se vivía en condiciones tan duras que fue para mí como haber estado en el cuartel antes del uso de razón» (Sánchez, 2003, p. 12).

14 «Es una infancia que sigue luego ligada a ese desarrollo de la Violencia. Mi padre, con mi madre, había alquilado una casa de inquilinato por ahí, donde duramos muy poco tiempo, pues a mi padre le fue muy mal económicamente acá. Se desesperó, se angustió. Claro, un campesino que no sabe manejarse en la ciudad, que no sabe vivir sino de la tierra, regresa a la tierra, así sea otra vez a la heredad de la cual estaba huyendo. Solo alcanzamos a estar unos pocos meses aquí en Bogotá. Regresamos a El Líbano, y cuando llegamos la situación estaba realmente peor» (Galindo; Valencia, 1999, p. 85).

15 Sobre el retorno al campo Sánchez dice: «Comenzamos a dar tumbos. Tengo esa imagen de nosotros buscando cuál era la vereda más calmada. Y la vereda más calmada duraba un mes, dos meses. Después, a los dos meses, a los tres, a los cinco, al año, de pronto, cuando uno está de buenas, pues a pasarse a otro sitio. Así duramos mucho tiempo, hasta cuando mi padre se compró una pequeña finquita, que la pudo comprar a cualquier precio, en el contexto mismo de la situación de la violencia. Una pequeña finca cafetera» (Galindo; Valencia, 1999, p. 84-87). 
de un sentirse extraño en tierra foránea. La experiencia de la Violencia adquiere nuevos matices, mediada también por los cambios políticos, en particular ocasionados por el Frente Nacional ${ }^{16}$.

En efecto, con el Frente Nacional la violencia ya no es vista por Sánchez como un enfrentamiento entre liberales y conservadores, sino como un residuo de este conflicto, a saber, la violencia de los bandole$\operatorname{ros}^{17}$; en este aspecto la experiencia de la violencia adquiere dos grandes matices: el sortear a los bandos en disputa $^{18}$, y la creación de mitos y

16 Con la dictadura de Rojas Pinilla se pretendió apaciguar infructuosamente brotes de caos de la Violencia. Sin embargo, el populismo de Rojas Pinilla y el fracaso del cese del conflicto llevó a que los dos partidos tradicionales pactaran turnarse y repartirse el poder político y burocrático; el Frente Nacional fue la ejecución de dicha coalición entre 1958 y 1974, con el cual se buscaba mantener en el poder a los partidos políticos tradicionales y garantizar el cese de la Violencia de carácter bipartidista.

17 «Nosotros no salimos nunca de la Violencia. Porque como mi papá era liberal, al comenzar el Frente Nacional él optó por ser un libera frentenacionalista, y salimos de la violencia liberal-conservadora para entrar en la violencia de los bandoleros» (Galindo; Valencia, 1999, p.p. 112)

18 «Nos tocaba bandearnos para manejar, por un lado a los militares, y por el otro, a los bandoleros. Como mi padre era frentenacionalista, resulta que ahora, en esta segunda etapa de la Violencia (o tercera, yo no sé qué etapa de la Violencia va a ser esta*), va a estar sometido al chantaje de estos bandoleros liberales que son, por su mismo origen, antifrentenacioanalistas. $A$ veces a mi padre le piden cuotas: quinientos pesos, cualquier cosa. Cuotas que para él le resultaban astronómicas. Fueron, digan ustedes, trece o catorce años de mucha angustia y zozobra permanente, sin lograr decir "vivimos un año tranquilo"» (Galindo; Valencia, 1999, p.p. 112-113)

* A pesar de las investigaciones realizadas por historiadores y sociólogos respecto a la Violencia, los debates sobre la representación de leyendas sobre los bandoleros ${ }^{19}$; al respecto Sánchez pone de manifiesto la forma como ciertos actores de la violencia eran visualizados o, si se quiere, representados por los miembros de la población civil, en carne propia, en esa ambigüedad que implica verlos míticamente como "héroes» (no en el sentido de «buenos», sino en el sentido de "lo que llegan a ser capaces») pero a la vez como «villanos» por el terror que podían inspirar ${ }^{20}$.

En este contexto empieza Sánchez sus estudios de primaria, que adelanta en la escuela de la vereda Minapobre, culminándolos en 1956. Gracias al apoyo de un tío se hace beneficiario a una beca, con la

esta época, o concepto o etapa de la historia colombiana son difíciles, sin duda alguna. La propuesta de hablar de distintas violencias, que insinúa aquí Sánchez, tiene que ver con la investigación adelantada por los violentólogos que se dio en la década de los 80; más adelante hablaremos de esta cuestión.

19 «A la casa en el campo, donde estábamos, siempre llegaba la gente de 'Desquite' y 'Sangrenegra', y para mí esos son personajes marcados encima de uno. 'Desquite' y 'Sangrenegra' eran mitos, pero al mismo tiempo eran personajes muy reales» (Galindo; Valencia, 1999, p.p. 112-113).

20 «Pienso que ahí hay cosas controvertibles y complejas de reconstruir. A uno le llegaban reflejos de las leyendas de algunos de esos personajes. Recuerdo que nosotros conversábamos con otros niños y otras personas del campo sobre gente que decía haber visto a 'Chispas'. Entonces... 'Chispas' iba en un caballo blanco.. 'Chispas', de repente, se desaparecía... 'Chispas' enfrentaba ejércitos que eran invulnerables... De 'Sangrenegra', 'Desquite' y los demás hay otras imágenes que la gente reproducía y que a uno también le llegaban. Por ejemplo, cuando describían a 'Desquite' (...) decían que era gordo. Ese era el prototipo del buen mozo. Que era un tipo muy educado (...) De 'Sangrenegra', no (...) La gente hablaba con terror de él» (Galindo; Valencia, 1999, p.p. 111-112). 
que continúa su secundaria en el norte de Antioquia (cf. Prado, 1995, p. 684). La preocupación por el tema de la violencia en esa época difícilmente podía darse; así lo atestigua Sánchez, diciendo que los estudios en letras ${ }^{21}$ que todo estudiante de secundaria debía realizar, no permitían ocuparse de ella (cf. Sánchez, 2004 , p. 35). Con esto se pone en evidencia cómo la experiencia vital de los campesinos o, si se quiere, incluso, la realidad cruenta del país, prácticamente es omitida por el sistema escolar que refuerza la experiencia de la violencia como algo que es mejor no pensar, que es preferible ignorar, y que explica también esos vacíos de la memoria, así como la ausencia de elaboración social de los eventos conflictivos que exponen también las continuidades que han hecho de la violencia el complejo fenómeno que es hoy.

En ese sentido, la memoria de la experiencia evidencia también una actitud de silencios, a modo casi de evasión ${ }^{22}$, transcritos con puntos suspensivos e interjecciones; con ello, Sánchez nos da prueba de lo difícil que es asumir una realidad compleja como la que se ha vivido y se dispone a relatar. El uso del término coloquial «vaina», usado por Sánchez, es el sentido colombiano para referirse a cuestiones indefinidas, difíciles de determinar o que no se logran comprender y de las cuales se desea su explicación o su no explicación, como cuando se pregunta con extrañeza: ¡¿qué es esa vaina?!

Pero también este término se usa para establecer simbólicamente una distancia con aquello que se menta; nombrar algo con el término «vaina» es como decir, «eso que no es conmigo», «eso que no quiero que sea conmigo»; en este caso designa situaciones que causan aversión y que se quisiera no haber vivido; me parece que ambos sentidos se encuentran presentes en esta interjección.

Por otra parte, Sánchez de manera serena y con la distancia propia de un intelectual, reconoce ese carácter de huida, no ya del hecho de haber sido desplazado, sino de no querer pen-

21 Sánchez se refiere a la lectura de obras como La lliada, La Eneida, La Divina Comedia, El Quijote, lecturas obligadas en esa época (cf. Sánchez, p. 35). Esto daría pistas para estudiar también los cambios que se han dado en los currículos desde esa época hasta la actualidad, en la cual, de manera improbable este tipo de obras se leen en los niveles educativos básicos o de media vocacional.

22 «Llegamos acá [Bogotá]. Los hermanos éramos en ese momento tal vez cuatro: los mayores dos... tres... tengo recuerdos borrosos... ¡Yo no quiero recordar esa vaina!» (Galindo; Valencia, 1999 , p.p. 112-113). 
sar en la violencia misma, de evadir esa realidad ${ }^{23}$. La huida la estructura Sánchez como concepto, no solo para configurar la memoria de su vivencia como marco general para representarse a sí mismo la Violencia, sino para conceptualizar una situación que él como colombiano considera que comparte con los demás colombianos: la evasión de esa realidad difícil de comprender y de asumir, que evoca esa interjección ¡Yo no quiero recordar esa vaina!

\section{La experiencia académica de la «ausencia» (de la reflexión) de la violencia}

Terminado el bachillerato, Sánchez vuelve a la capital colombiana e ingresa a la Universidad Nacional. Se incorpora en 1965 y comienza a estudiar dos carreras simultáneas: Derecho y Filosofía, inclinándose más por la segunda.

Esta época, lo recalca el autor, fue de poco contacto «conceptual» con el tema de la violencia o de las situaciones conflictivas. Sin embargo, su inclinación por lo social hizo que Sánchez formara parte del Frente de Estudios Sociales, un influyente grupo estudiantil que llegó a editar una revista Ilamada Publifes; este grupo alcanzó una gran participación po-

«Crecí huyéndole a la violencia, pero metido en ella todo el tiempo» (Sánchez, 2003, p. 11; subrayado del autor). "Creo que mis tendencias iniciales, como la de tantos colombianos, fueron eludirla, dejarla suspendida» (Sánchez, 2004, p. 35; subrayado del autor). lítica en el consejo estudiantil de la universidad; sin embargo, este consejo fue disuelto por el entonces presidente Carlos Lleras (cf. Sánchez, 2004, p. 39). Ambas cosas se complementaron para él, y gracias a ello entró en contacto académico con las obras de autores como Marx, Lenin, Hegel, Mao-Tsé, Althuser, Gramsci, Weber y Marcuse.

Pero la importancia que tuvo la militancia en ese proceso fue fundamental, sobre todo en el sentido existencial: "La militancia era también una manera de estar en el mundo; de conectar nuestros temas nacionales con los grandes conflictos internacionales (aunque a menudo con trasposiciones muy mecánicas)» (Sánchez, 2004, p. 38).

Como se ve, los intereses académicos de Sánchez, si bien tenían rasgos políticos y sociales, no tenían como objeto principal la Violencia o la violencia como fenómeno. Si bien Sánchez hace referencia a las pedreas estudiantiles y a las intervenciones de la fuerza pública en la Universidad Nacional, sus referencias a ello son tangenciales, lo que también evidencia cierto lapso de desinterés por el objeto como tal. Él mismo reconoce esta situación; será en la siguiente etapa en la que se reencontrará con esa realidad y, por supuesto, con su pasado.

\section{La experiencia de encaramiento de la memoria de la Violencia}


No es, curiosamente, la experiencia de la violencia (o de la Violencia) la que llevará a Sánchez a pensarla como fenómeno social o político. Serán circunstancias académicas las que prácticamente propiciarán que tenga que pensar casi que obligadamente los fenómenos conflictivos del país y, por supuesto, su propia experiencia ya antes narrada y que él mismo reconoce que había evadido ${ }^{24}$.

En efecto, como filósofo poseía conocimientos de naturaleza abstracta sobre lo social; por su parte, el Derecho, concentrado más en la enseñanza y el aprendizaje de códigos y procedimientos de ley, tampoco daba herramientas conceptuales para pensar fenómenos de esta naturaleza. Por ser el mejor estudiante de su promoción se hizo merecedor de una beca de la Universidad Nacional que le permitió ir a Inglaterra en 1972 para cursar estudios de historia y ciencia política.

Esto implicará una experiencia de vida no ya con la violencia como tal, sino con sus difíciles recuerdos que podrían caracterizarse como autoanálisis o catarsis. Sánchez realza la problemática de la violencia personificándola o metaforizándola como un monstruo que lo ha poseído en dos sentidos: vivencial y académicamente ${ }^{25}$.

La posesión significa la imposibilidad de ser dueño, de lograr manejar o de desprenderse del dominio de algo. Sin embargo, esto se sitúa en la posibilidad (no fácil) de hacer -a través de la investigación y el ejercicio académico- la «liberación» o «purificación» (catarsis, en griego) de esas marcas, o mejor, en que ya no sea la violencia la que domina, cual monstruo, sino que pase a ser la dominada gracias al ejercicio académico; es una posibilidad de objetivar la violencia, y no ella al sujeto ${ }^{26}$.

Esa circunstancia obligada hace que en Inglaterra, Sánchez tenga la oportunidad de enriquecer sus conocimientos al lado de pensadores como Hobsbawm, Thompson, Hill (Sánchez, 2004 , p. 36); sus investigaciones le obligaron a volver la mirada

24 «Vano resultó el intento de evasión y de deshacerme de ese pasado traumático. Apareció como objeto intelectual, paradójicamente estando lejos de Colombia» (Sánchez, 2003, p. 14).

25 «Desde entonces quedé poseído por la problemática de la violencia: mis estudios se volvieron en cierta manera autoanálisis, exorcismo o catarsis de mis temores y aprehensiones infantiles, intento (tal vez fallido) por entender ahora ese monstruo que dominó mis primeros años y que ha seguido marcando la historia del país y de mi propia biografía» (Sánchez, 2003, p. 14)

26 "La consigna de ese momento como académico y como víctima de la violencia era la reapropiación de ese pasado, donde había quedado enredada su infancia» (Pardo, 1995, p. 685) 
al mundo rural (cf. Sánchez, 2004, p. 41), al igual que los trabajos sobre la protesta rural en América Latina en autores como Landsberger, Stavenhagen, Huizer, para plantear interrogantes y postular hipótesis que darían pie al desarrollo de sus trabajos.

De manera que de regreso a Colombia, en 1976, ejerce la docencia en la Universidad Santo Tomás y en la Universidad Nacional; vuelve al Tolima y se encuentra con investigaciones afines a su trabajo que le permiten también culminar los li$\operatorname{bros}^{27}$ que desarrollaban hipótesis enriquecidas con trabajo de campo y búsqueda en archivos. De igual modo, como docente de historia, se vio obligado a investigar sobre historia de Colombia y se enriqueció con la tradición ahora francesa de la Escuela de los Anales ${ }^{28}$.

Su trayectoria académica se vio enriquecida también por su experiencia como profesor visitante de universidades europeas y norteamericanas, al igual que pudo establecer contactos con importantes colombianistas como Daniel Pécaut, Charles Bergquist y Christopher Abel $^{29}$. Sin embargo, y entre tanto,

27 Entre ellos tenemos: Los bolcheviques del Libano (1976); Las ligas campesinas en Colombia (1977); Bandoleros, gamonales y campesinos (1983), este último en coautoría con Donny Meertens.

28 «Aprendí de la Escuela de los Anales que la misión del historiador no era simplemente reconstruir el pasado, sino reinterpretarlo» (Sánchez, 2004, p. 45).

29 «Las intermitentes estadías en el exterior contribuyen a ampliar insospechadamente nuestros horizontes intelectuales, nos obligan a elevar el rigor y la claridad conceptual y expositiva, con- el conflicto colombiano había adquirido nuevos matices: la Violencia bipartidista había «evolucionado» a la violencia de los bandoleros, y ésta a la violencia guerrillera, a la que pronto en la década de los 70 y 80 se le sumarán las violencias de los carteles del narcotráfico y del paramilitarismo, todo ello en el marco de la Guerra Fría que implicó el contexto mundial.

\section{La experiencia del recuerdo en la comisión de estudios sobre la violencia: de la riqueza teórica a la saturación de memoria}

Hacia 1982 los grupos guerrilleros se habían expandido vertiginosamente; a pesar de los procesos de amnistía en ese mismo año con el M19, así como el cese al fuego de las Farc en 1984, los procesos de reconstrucción del orden social no se consolidaron plenamente, en parte por las ambigüedades de estos grupos armados y del gobierno, así como por la creciente influencia del narcotráfico y del paramilitarismo en sectores políticos. En este difícil contexto y teniendo una consolidada trayectoria intelectual y académica a nivel nacional e internacional, Sánchez fue Ilamado en 1986 a coordinar el núcleo fundador del Instituto de Estudios Políticos y Re-

diciones indispensables para que nuestros escritos puedan acceder a las revistas y las editoriales internacionales» (Sánchez, 2004, p. 45). 
laciones Internacionales (IEPRI) de la Universidad Nacional; y el año siguiente fue llamado por el Ministerio de Gobierno y Colciencias a conformar una comisión para investigar la violencia en el país, trabajo que produjo como fruto el texto Colombia: violencia y democracia.

Esto implicó un viraje en su forma de abordar el tema de la violencia. Si en su etapa de filósofo y abogado la violencia estuvo prácticamente ausente; si la beca en Inglaterra le obligó a pensar el tema de la violencia desde su dimensión histórica, será la comisión de «violentólogos» la que llevará a Sánchez a pensar el tema políticamente ${ }^{30}$. A raíz de esto, la misma concepción de la violencia que Sánchez había estructurado en torno a la cuestión de la confrontación guerrillera se desplaza a la idea de la multiplicidad de violencias ${ }^{31}$.

Sin embargo, estos trabajos trajeron como consecuencia también una experiencia de saturación de la memoria que implicó varias cosas: la primera, la sensación de sufrir el tema, de tener que soportarlo ${ }^{32}$; la segunda, un nuevo deseo de distanciarse del tema (quizás de evadirlo nuevamente) ${ }^{33}$; y tercero, la experiencia de sentirse forzado a reconstruir una pesadilla ${ }^{34}$.

Sin embargo, estando en el exterior, huyendo nuevamente del tema, la violencia cometida por los carteles de Medellín y Cali, el terrorismo perpetrado por los capos del narcotráfico, junto con la violencia paramilitar y los continuos ataques de las gue-

30 «Para mí la experiencia más central en los 80 fue la participación en la famosa comisión esta de los violentólogos que, entre otras cosas, a mí me lanzó un poco de la situación de historiador a la situación de politólogo. Realmente, hasta ese momento para mí la violencia era un objeto de preocupación de carácter histórico. Un objeto de reflexión de pasado. De revisión de la historia nacional, etc. La formación de la comisión me puso en contacto con un grupo de personas - antropólogos, politólogos, militares, otros historiadores-, que estaban reflexionando sobre cosas muy del momento».

31 «Digamos que esa comisión me metió casi que forzosamente, muy en la idea de las nuevas violencias, que era el tema central que planteó el libro. Hasta ese momento, la idea de violencia se identificaba con la tradicional visión de la gran violencia política o la confrontación guerrillera. Pero el aporte fundamental de ese libro fue, entre otras cosas, poner sobre el tapete, poner en evidencia, una cosa que ya era un hecho: la multiplicidad de las violencias» (Galindo; Valencia, 1999, p.p. 195-196)

32 «Comencé a sentir un cierto cansancio con el tema, una sobresaturación, un cierto sentido de aprisionamiento. Un sentimiento de que, por el destino, había resultado metido en el tema, sufriéndolo» (Galindo; Valencia, 1999, p. 261).

33 «En el 89, dos años después de la comisión de Estudios sobre la Violencia, me fui para Francia y otros sitios de Europa como Holanda, con la idea ya de romper con el texto [Colombia: violencia y democracia] y con el tema» (Galindo; Valencia, 1999, p. 261).

34 «Para mí mi trabajo de investigación ha significado como una especie de reconstrucción de una pesadilla. Esa experiencia personal indudablemente ha permanecido viviendo en la alcoba. Habrá muchas otras situaciones parecidas, pero esta experiencia personal ha pesado mucho en la opción por este tema de investigación» (Galindo; Valencia, 1999, p. 261). 
rrillas en uno de los puntos más álgidos que ha alcanzado el conflicto colombiano reciente que significó masacres, atentados sistemáticos contra partidos políticos de izquierda, así como el asesinato de candidatos a la presidencia, hace que en el extranjero lo llamen a hablar del tema nuevamente ${ }^{35}$.

\section{La experiencia de autorreflexión de la memoria}

En el proceso de desmovilización de los paramilitares que comenzó con el gobierno del entonces presidente Uribe, después de un fallido proceso de paz entre el gobierno de Pastrana y las Farc, desafíos de comprensión del conflicto colombiano y sobre los rasgos y procesos de la violencia son más que vigentes ${ }^{36}$.

En este mismo contexto, la apuesta de Sánchez en su trayectoria ha sido una revisión o autorreflexión de sus propias apuestas históricas y

35 «Es justamente en ese periodo, del 89 al 92-93, cuando (...) la violencia adquiere nuevas dimensiones (...) Entonces en Europa, yo, que estaba en proceso de liberarme del tema, me vi obligado a seguir hablando de él. Si me invitaban a Ámsterdam, si mi invitaban a Londres o a mi propio país, era para seguir trabajando sobre el tema» (Galindo; Valencia, 1999, p.p. 225-226). Fruto de esas reflexiones publicó el libro Guerra y política en la sociedad colombiana.

36 «El súbito proceso de negociación con los paramilitares y las frustradas negociaciones con la insurgencia vuelven a poner al país frente a los problemas decisivos de administración de su pasado, para decidir su futuro. Memoria, amnistía, olvido, impunidad son otra vez terreno obligado de encuentro entre los historiadores, los hacedores de paz, entre analistas sociales y políticos» (Sánchez, 2004, p. 47) políticas acerca del tema de la violencia en Colombia ${ }^{37}$; surge pues un nuevo desplazamiento: ya no se trata de indagar sobre la Violencia, la violencia guerrillera o las múltiples violencias; se trata de reflexionar acerca de la memoria que se ha tejido sobre ellas.

Esto sin duda responde también a lo que académicamente se ha denominado el boom de la memoria, sobre todo por el auge de las investigaciones que en esta orientación se han dado en el cono sur o en el contexto centroamericano. El interés, en este sentido, es precisamente desplazarse hacia la experiencia de las víctimas.

Si bien el conflicto continúa, ya no se trata de estudiar procesos históricos; para Sánchez la cuestión se sitúa más bien en la memoria, en las huellas, en las formas como se administra el pasado. Vuelto Sánchez hacia este nuevo viraje, y en el contexto del proceso de desmovilización de los paramilitares, sus intereses investigativos empalmarían perfectamente con el interés de la CNRR, dirigida por su colega en el IEPRI, el también violentólogo Eduardo Pizarro León-Gómez.

Como se ve, es esta la apuesta en la que se inscriben las reflexiones más recientes sobre la memoria; esto se visibiliza también en las fuentes que

37 «La última fase de mi formación se ha derivado de una reflexión circunstancial sobre mi propia obra, y tiene como eje problemático la memoria: es decir, la importancia, ya no tanto de los hechos o de los procesos en sí mismos, sino de las huellas en el curso de la acción presente» (Sánchez, 2004, p. 47). 
hemos usado: en 1999 apenas encontramos la recopilación de las narrativas; en el momento presente encontramos reflexiones más pausadas y sosegadas sobre la cuestión. La memoria, entonces, se ha situado como centro de reflexión y debate académico.

\section{Algunas reflexiones finales}

El presente trabajo nos ha permitido evidenciar la trayectoria de la experiencia de la memoria que ha tenido Gonzalo Sánchez respecto a la violencia; hemos visualizado cómo en el recorrido intelectual de este pensador, el recuerdo de las experiencias límite que él vivencia van transitando un camino azaroso que oscila entre la evasión y el obligado enfrentamiento que provocan circunstancias intelectuales y académicas.

En este sentido, la memoria como tema solo se consolida recientemente como apuesta intelectual debido al contexto social del investigador, pero también por el boom de la memoria que se ha dado recientemente.

Con relación a cómo experiencias límite que se recuerdan han incidido o contribuido en los aportes académicos que ha estructurado Sánchez, podemos agregar que su narrativa vivencial no solo da cuenta del fenómeno en un sentido histórico y social con varios elementos, sino que estos mismos elementos están atravesados por la experiencia: en este sentido la violencia es experimentada como agresión no solo tangible física o verbalmente; el terror y el desplazamiento forzado son agresiones $y$, por lo mismo, violencia. De manera, pues, que se puede hablar de una primera experiencia de conceptualización de la Violencia a partir de la memoria de la experiencia del desplazamiento forzado: la violencia es agresión que implica desterrar, intimidar y mantener en la zozobra y la confusión.

Por otra parte Sánchez, de primera mano, nos relata la situación en la que quedaban los campesinos; esta lógica no ha desaparecido de los procesos de conflicto en la actualidad: sin poder tomar partido por ningún bando, y a la vez presionados desde distintos frentes. Estas polarizaciones han tenido y tienen repercusiones graves para la población civil; prueba de ello son los asesinatos selectivos que se han presentado en las últimas décadas de parte de paramilitares, guerrilla, narcotraficantes y miembros de la fuerza pública ${ }^{38}$. 
En este sentido, el estudio de dicha trayectoria permite visibilizar la memoria como una experiencia vital en la que, en particular el desarraigo -que ha quedado en la memoria de las víctimas y del que Sánchez también es ejemplo- no es una vivencia simple; en efecto, el ser humano establece una conexión vital, una relación profunda con aquello que le da sustento; sustento entendido no solo como manutención, sino como «raíz»" Esto ayudaría también a comprender unas continuidades en los fenómenos sociales. En el contexto de la violencia los campesinos se vieron, se han visto y se ven obligados a vender su tierra a cualquier precio; en circunstancias peores se ven obligados a dejar todo abandonado, literalmente. Esta situación ha beneficiado, en ocasiones, a los pequeños campesinos, pero sobre todo a los latifundistas, y en la actualidad, a multinacionales y narcotraficantes ${ }^{40}$. Estas conexiones y continuidades, así como la experiencia de evasión y de enfrentamiento obligado, evidencia no solo

39 «Nos tornamos pensativos y preguntamos: ¿no depende el florecimiento de una obra cabal del arraigo a un suelo natal? Johann Peter Hebel escribió una vez: "Somos plantas -nos guste o no admitirlo- que deben salir con las raíces de la tierra para poder florecer en el éter y dar fruto". (Obras, ed. Altwegg, III, 314). El poeta quiere decir: para que florezca verdaderamente alegre y saludable la obra humana, el hombre debe poderse elevar desde la profundidad de la tierra natal al éter. Éter significa aquí el aire libre del cielo alto, la abierta región del espíritu» (Heidegger, 1959).

40 Para consultar toda la producción de este grupo véase http://www.memoriahistorica-cnrr.org. $\mathrm{co} /$. la complejidad del fenómeno, sino la urgente necesidad de seguir pensando en direcciones que posibiliten nuevos y más amplios espacios de reflexión ética y política.

\section{Referencias}

Galindo, M., Valencia, J. (1999). En carne propia. Ocho violentólogos cuentan sus experiencias como víctimas de la violencia. Bogotá: Intermedio.

Pardo, C. (1995). Protagonistas del Tolima. Siglo XX. Bogotá: Pijao.

Sánchez, G. (2004). El inacabado proceso de formación de un historiador. En: Camacho Guizado, Á. (Ed.). Artesanos y disciplinas: hacer ciencias humanas en Colombia. Coloquio del CESO, Bogotá.

(2003). Guerras, memoria e historia. Bogotá: ICANH.

Heidegger, M. (1959). Serenidad. Recuperado el 1 de noviembre de 2008. Disponible en http:// www.heideggeriana.com.ar/ textos/serenidad.htm

Jelin, E. (2003). Los derechos humanos y la memoria de la violencia política y la represión: la construcción de un campo nuevo en las ciencias sociales. Buenos Aires. Cuadernos del IDES, No. 2, octubre de 2003.

(2001). Los trabajos de la memoria. Madrid: Siglo $\mathrm{XXI}$.

Grupo de Memoria histórica - CNRR (2009). Recordar y narrar el 
conflicto. Herramientas para reconstruir memoria histórica. Bogotá: Fotoletras.

gotá: Planeta. (2008). Trujillo. Una tragedia que no cesa. Bo-

Ricoeur, P. (2002). La memoria, la historia el olvido. Traducción de Agustín Neira. Buenos Aires: Fondo de Cultura Económica.

Gadamer, H. G. (1960). Verdad y método. Fundamentos de una hermenéutica filosófica. Salamanca: Sígueme. 